\title{
“COVID-19/SARS-CoV-2 virus spike protein-related delayed inflammatory reaction to hyaluronic acid dermal fillers: a challenging clinical conundrum in diagnosis and treatment"
}

\author{
Girish Gilly Munavalli ${ }^{1,2} \cdot$ Rachel Guthridge $^{1} \cdot$ Siri Knutsen-Larson ${ }^{3} \cdot$ Amy Brodsky $^{4} \cdot$ Ethan Matthew $^{3}$. \\ Marina Landau ${ }^{5}$
}

Received: 13 January 2021 / Revised: 20 January 2021 / Accepted: 21 January 2021 / Published online: 9 February 2021

(c) The Author(s), under exclusive licence to Springer-Verlag GmbH, DE part of Springer Nature 2021

\begin{abstract}
We present the first reported cases of delayed inflammatory reactions (DIR) to hyaluronic acid (HA) dermal fillers after exposure to the COVID-19 spike protein. DIR to HA is reported to occur in the different scenarios including: secondary to poor injection technique, following dental cleaning procedures, following bacterial/viral illness, and after vaccination. In this report of 4 cases with distinct clinical histories and presentations: one case occured following a community acquired COVID19 infection, one case occured in a study subject in the mRNA-1273 clinical phase III trial, one case occurred following the first dose of publically available mRNA-1273 vaccine (Moderna, Cambridge MA), and the last case occurred after the second dose of BNT162b2 vaccine (Pfizer, New York, NY). Injectable HA dermal fillers are prevalent in aesthetic medicine for facial rejuvenation. Structural modifications in the crosslinking of HA fillers have enhanced the products' resistance to enzymatic breakdown and thus increased injected product longevity, however, have also led to a rise in DIR. Previous, DIR to HA dermal fillers can present clinically as edema with symptomatic and inflammatory erythematous papules and nodules. The mechanism of action for the delayed reaction to HA fillers is unknown and is likely to be multifactorial in nature. A potential mechanism of DIR to HA fillers in COVID-19 related cases is binding and blockade of angiotensin 2 converting enzyme receptors (ACE2), which are targeted by the SARS-CoV-2 virus spike protein to gain entry into the cell. Spike protein interaction with dermal ACE2 receptors favors a pro-inflammatory, loco-regional TH1 cascade, promoting a CD8+T cell mediated reaction to incipient granulomas, which previously formed around residual HA particles. Management to suppress the inflammatory response in the native COVID-19 case required high-dose corticosteroids (CS) to suppress inflammatory pathways, with concurrent ACE2 upregulation, along with high-dose intralesional hyaluronidase to dissolve the inciting HA filler. With regards to the two vaccine related cases; in the mRNA-1273 case, a low dose angiotensin converting enzyme inhibitor (ACE-I) was utilized for treatment, to reduce pro-inflammatory Angiotensin II. Whereas, in the BNT162b2 case the filler reaction was suppressed with oral corticosteroids. Regarding final disposition of the cases; the vaccine-related cases returned to baseline appearance within 3 days, whereas the native COVID-19 case continued to have migratory, evanescent, periorbital edema for weeks which ultimately subsided.
\end{abstract}

Keywords COVID-19 · Hyaluronic acid fillers · Delayed inflammatory reaction · ACE2 - mRNA vaccine · ACE receptor · ACE receptor inhibitor

\section{Introduction}

Girish Gilly Munavalli

gmunavalli@carolinaskin.com

Extended author information available on the last page of the article
The usage of injectable dermal hyaluronic acid (HA) fillers for aesthetic facial rejuvenation and contour enhancement of superficial wrinkles, deep folds, and volume loss has risen $78 \%$ over the last 7 years [1]. It is predicted to continue to rise. Market size is expected to gain market growth in the forecast period of 2020-2025, with a compound annual growth rate of $7.2 \%$ in the forecast period of $2020-2025$ and 
will expected to reach USD 1324.7 million by 2025 , from USD 1004 million in 2019 [2].

Simultaneously, modifications in crosslinking agent technology over the last 10 years have rendered HA filler products more resistant to normal innate dermal enzymatic degradation processes, increasing longevity and decreasing dermal transit time [3]. Conceptually, HA fillers can be seen as long-lasting implants which can persist as long as 2-5 years or longer in certain facial anatomic areas such as the malar cheeks, midface, and tear trough, in varying levels of the dermis, subcutis, and supraperiosteum [4]. Because of this longevity, delayed inflammatory reactions (DIR) to HA filler within the skin have been reported to occur [5]. The exact mechanism of action for the delayed reaction is unclear, likely immune-mediated and multifactorial in nature. DIR to fillers following infectious processes, such as viral illness, have been reported [6].

As of this article submission, the number of COVID19 infections with the SARS-CoV-2 virus continue to rise worldwide. The 1273 amino acid long viral spike protein of this virus targets angiotensin converting enzyme 2 (ACE2) for anchoring and intracellular invasion [7]. Clinical presentation and manifestations in distinct organ tissue systems of the body vary tremendously and are still being elucidated. Organ systems with high constitutively expressed ACE2, such as the pulmonary lungs and the endothelial lining of the vascular system, are particularly at risk for tissue damage [7]. In human studies, it has been reported that ACE2 is ubiquitously expressed in all tissues of the body [8]. Interestingly, Li et al. showed in 31 human tissues, between gender and across age ranges, the skin is moderately high in expression of ACE in comparison to other body organs [8]. In murine models, dermal fibroblasts are shown to express ACE, possibly linking areas of active focal dermal fibrosis with increased localized skin ACE concentration [9]. ACE plays a critical role as a immuno-regulator in the conversion of Angiotensin I to the proinflammator metabolites, Angiotensin II-VII. As such, localized blockade of dermal ACE could results in a proinflammatory cascade causing inflammation, vasoconstriction, fibrosis, proliferation, and oxidative stress in the tissue reaction [10]. In this article, we present the first reported cases of DIR for facial HA filler following exposure to COVID-19 spike protein.

\section{Case 1}

Patient one is a 50-year-old female with a medical history of recalcitrant scalp dermatitis controlled with periodic dupliximab (Dupixent, Regeneron, Tarrytown, NY) injections. She received two HA fillers of varying particle size with,4-butanediol diglycidyl ether crosslinking, which were injected into cheeks, lips, and tear troughs over the course of
12 months by nurse injector (Restylane Lyft and Restylane L, Galderma,). Fifteen days after the last HA filler injections, the patient tested positive for COVID-19 by PCR nasal swab on August 7, 2020 after having symptoms of sore throat and mild cough for 3 days, no fever. Two weeks later, the patient reported lips burning like sunburn and significant swelling to lips and cheeks and tear troughs. The patient reported severe periorbital swelling, was evaluated by primary care and treated with an IM kenalog injection for suspected food allergy. The patient's facial edema, erythema, and tenderness continued to worsen and the patient returned back to the clinic of treatment. Hylenex, in the amount of $2 \mathrm{ccs}$, was injected to tear troughs, upper lip and marionettes. The patient reported burning and pain during hylenex injections. After transient improvement, 3 days later edema and induration flared in cheeks (right worse than left). The patient was prescribed $40 \mathrm{mg}$ prednisone for 14 days and $100 \mathrm{mg}$ doxycycline daily for 14 days with mild improvement. She presented to our clinic on September 22, 2020. On exam, the right cheek was erythematous and indurated, nodules present in marionettes. Ultrasound findings of the right malar cheek showed dermal/subcutaneous collection of well defined, lucent, foreign body material, located approximately $1 \mathrm{~cm}$ from the skin surface (Fig. 1a). Using duplex ultrasound guidance, right cheek was injected with $0.6 \mathrm{cc}$ Hylenex and left cheek injected with $0.3 \mathrm{cc}$ of Hylenex. Patient presented 3 days later with persistent edema and erythema to right cheek and an additional $0.2 \mathrm{cc}$ of Hylenex was injected. A week later the erythema, edema and tenderness had improved (Fig. 1b); however, the patient reported intermittent edema to tear troughs. As patient continued to experience evanescent swelling and tenderness of the medial, infraorbital cheeks, alternate treatment options were considered. A radiofrequency microneedling device adjusted to depths of $3.5 \mathrm{~mm} / 2.5 \mathrm{~mm} / 1.5 \mathrm{~mm}$ with an insulated 48 pin needle array (Genius, Lutronic Corp, Goyang, South Korea) was used in an attempt to thermally dissipate any residual HA filler. Additionally, she was prescribed Clarithromycin $500 \mathrm{mg}$ bid $\times 2$ weeks and $40 \mathrm{mg}$ Prednisone taper over 1 week. Although marked clinical improvement was noted after this regimen (Fig. 2), small foci of inflammation still waxed and waned. On subsequent visits to control the inflammation, additional intralesional triamcinolone acetamide $(10 \mathrm{mg} / \mathrm{cc})$ and Hylenex were used. As of the last treatment, the patient continued to report intermittent mild edema under the eyes.

\section{Case 2}

A 51-year-old healthy female received HA fillers (Voluma, Volbella Allergan, Irvine, CA) by nurse injector. Injections were performed in the into the earlobes, nasolabial folds 
Fig. 1 Clinical and duplex ultrasound improvement after a series of recombinant hyaluronidase injections. Note the improvement in facial erythema and swelling before injections (a) and after (b). Ultrasound (arrow) shows resolution of dermal opaque hyaluronic acid following hyaluronidase injections
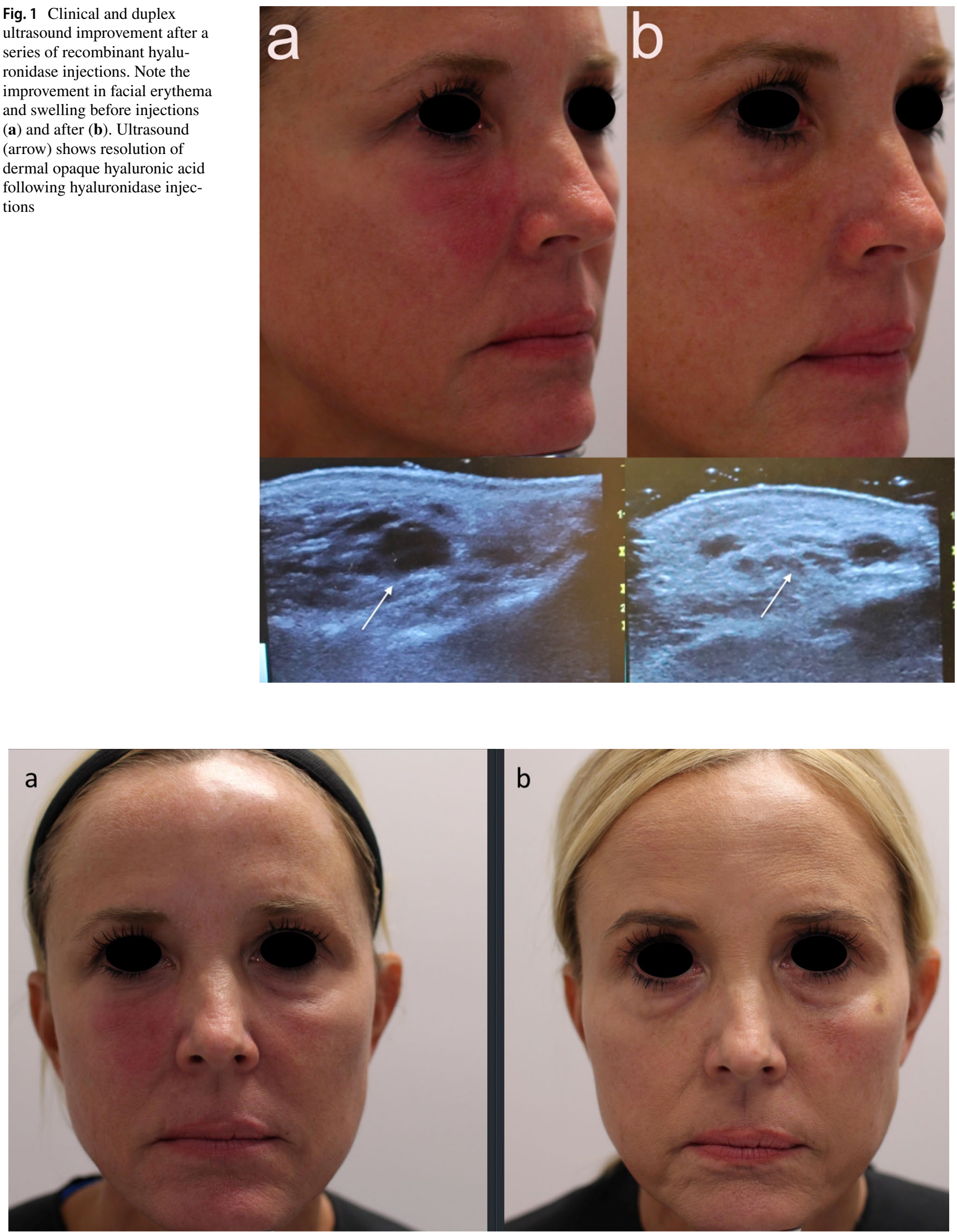

Fig. 2 Clinical improvement in Case 1 before (a) and after (b) prolonged course of multiple therapeutic intervention 
(NLF), tear troughs, malar and mid cheeks and upper/ lower lips over the course of 18 months, totaling approximately 4 ccs total of filler. By history, 5 weeks after the last filler injection to cheeks and lips, she enrolled into the Moderna Phase III pivotal clinical trial of investigational vaccine (mRNA-1273) for COVID-19. As reported, the trial design was double-blinded and placebo controlled. Subjects were randomly assigned $1: 1$ to receive two intramuscular (IM) injections either two $\times 100 \mu \mathrm{g}$ of mRNA1273 or two placebo saline injections. She received the first blinded IM injection on August 4, 2020 and distinctly remembered receiving a thick, viscous injection, which caused immediate injection site pain and irritation. She developed localized arm pain over the course of 24-48 h following the injection which subsided. Eight days later, she presented to a local oculoplastic surgeon with facial edema, erythema and tenderness of the periorbital area and malar cheek (Fig. 3). With subsequent progression of swelling and formation painful indurated plaques and nodules, she underwent a head CT scan which showed findings of mild soft tissue swelling involving the right inferior orbit/eyelid without drainable fluid collection (Fig. 4). The patient was prescribed Medrol Dosepak (MethylPREDNIsolone) and Doxycycline. Two weeks later edema and pain of the cheeks increased, prompting return to the original injector's office for additional evaluation and management. At that time, lymphatic drainage and cupping were performed. Each cheek was injected with $1 \mathrm{cc}$ of recombinant hyaluronidase 150 U/cc (Hylenex,Halozyme, San Diego CA). Three days later the earlobes, nasolabial folds and lips became more edematous, indurated and painful (Fig. 5a, b); three additional cc of Hylenex was injected to NLF and earlobes. Edema persisted and 2 days later an additional $10 \mathrm{cc}$ of Hylenex was injected $(2.5 \mathrm{cc}$ in

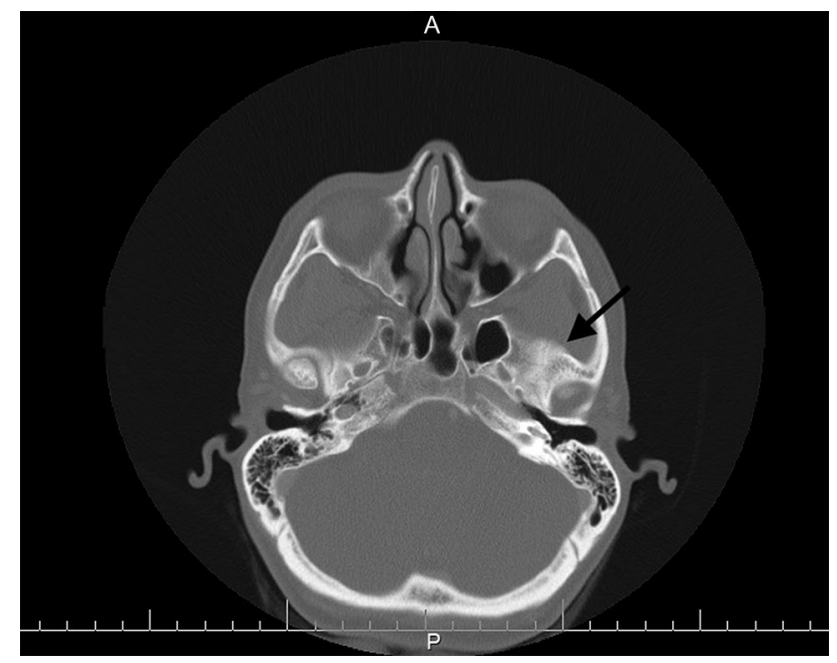

Fig. 4 CT scan at the level of the orbital rim. Arrow showing right sided soft tissue swelling

each NLF, $1.5 \mathrm{cc}$ in each earlobe and $2 \mathrm{cc}$ in lower lip). The patient presented to our clinic on August 31, 2020. Upon clinical examination, the lips, cheeks, tear troughs and earlobes were tender, indurated and erythematous (Fig. 6). A total of $0.8 \mathrm{cc}$ of intralesional 5-Fluorouracil (Adrucil, $50 \mathrm{mg} / \mathrm{cc}$ ) was injected into the upper lip. The patient was prescribed an $60 \mathrm{mg}$ Prednisone taper over 12 days and $10 \mathrm{mg}$ hydroxyzine as an antihistamine. Of note, the patient had no prior history of heritary or drug-induced angioedema. After 4 days on prednisone the pain and edema in lips decreased. As infection was a consideration, sulfamethoxazole and trimethoprim (chosen due to a prior medical history of antibiotic sensitivity and pseudomembranous colitis) was prescribed and a
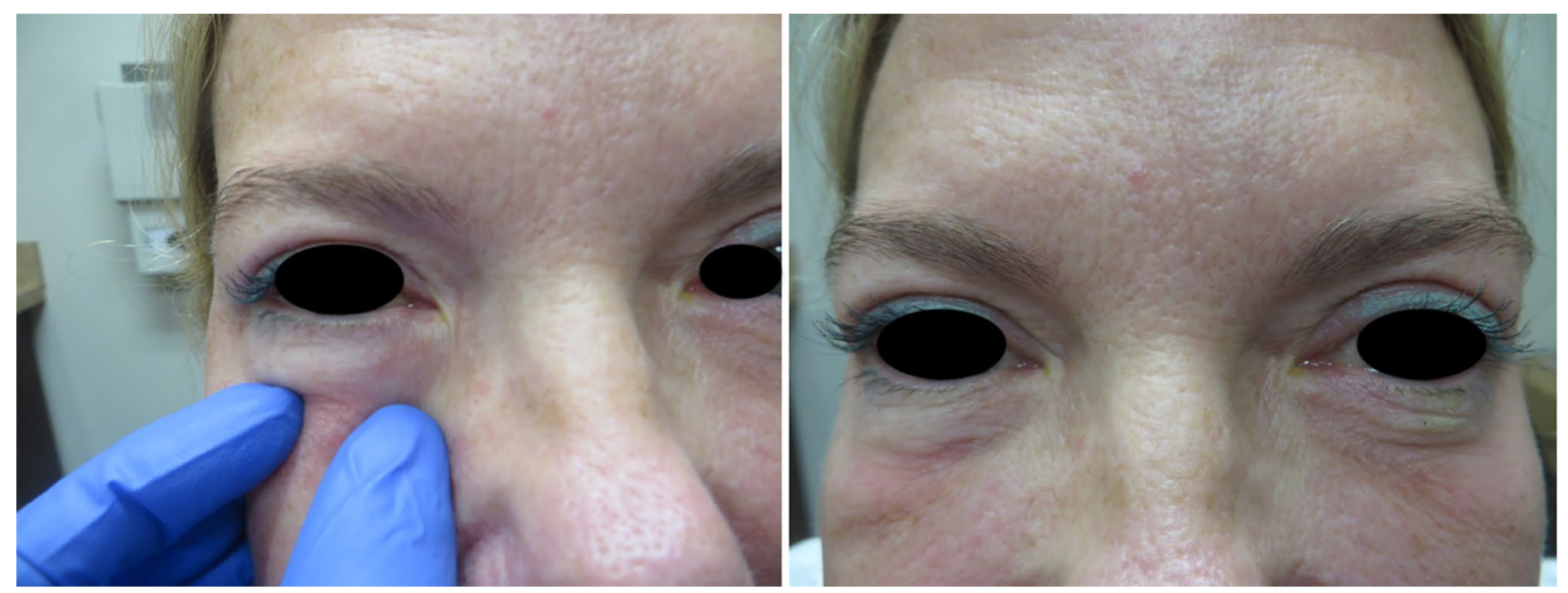

Fig. 3 Swelling and edema of the lower lid and cheek as the presenting signs of in Case 2 


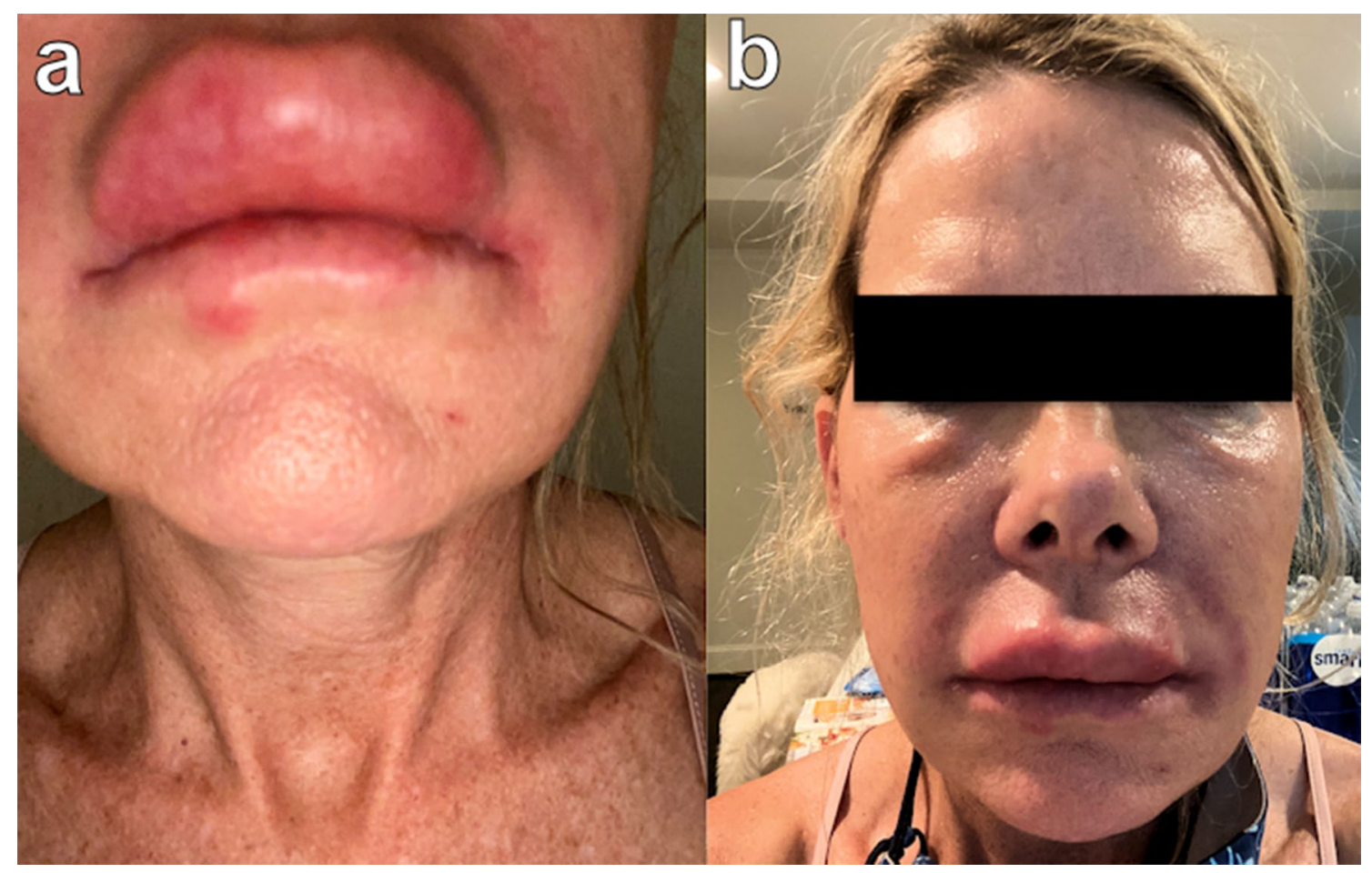

Fig. 5 Phone camera "selfie" images show the extent and severity of inflammation and swelling of the face and lips

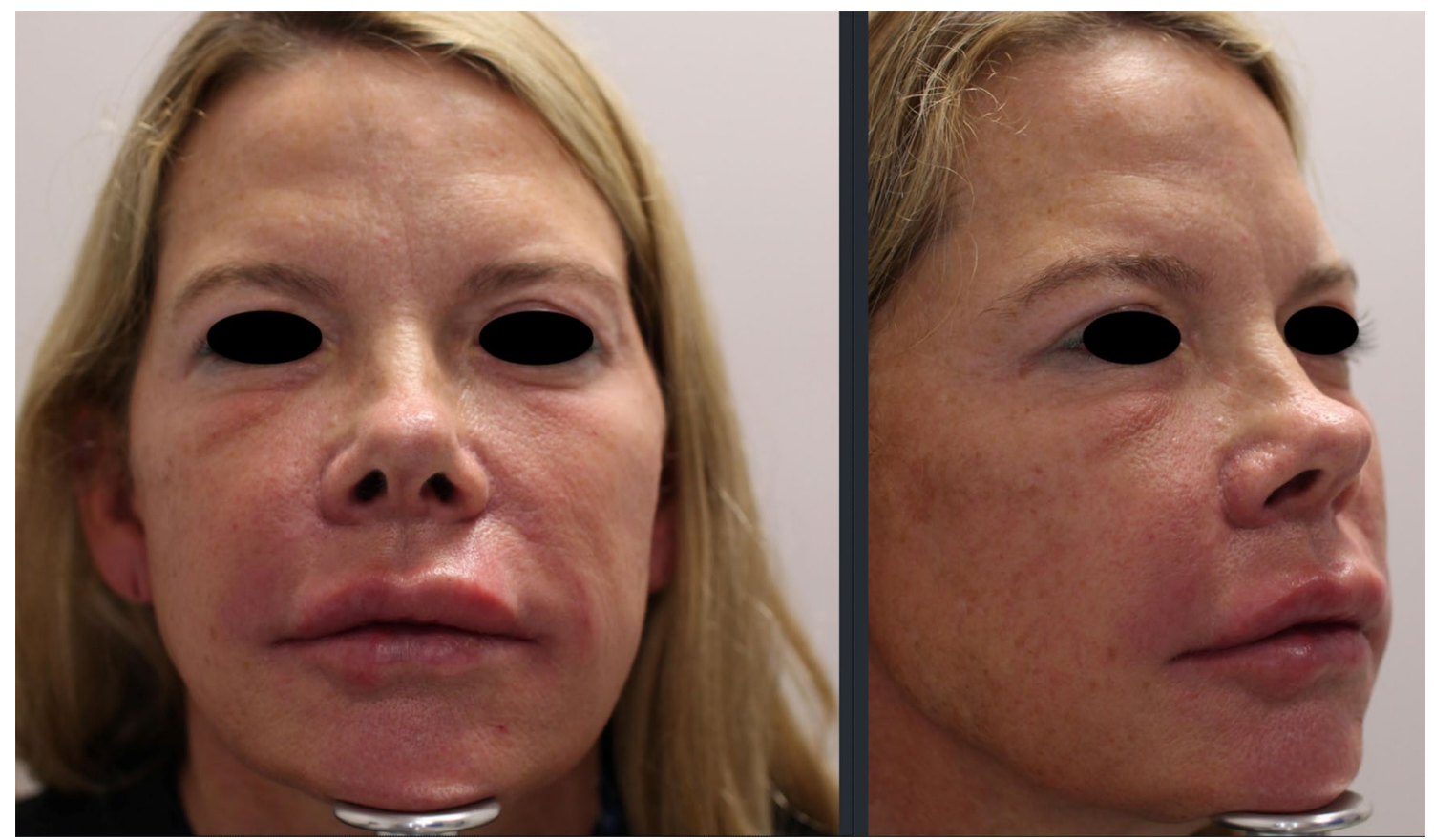

Fig. 6 Incremental improvement following serial injections of hyaluronidase and oral prednisone

total of $4 \mathrm{cc}$ compounded bovine hyaluronidase at $150 \mathrm{U} /$ cc (O'Brien Pharmacy, Mission, KS) was injected to tear troughs, lips, and cheeks. The following day, with marginal improvement, an additional of $5.5 \mathrm{cc}$ bovine hyaluronidase was injected to tear troughs, lips, NLF and cheeks and $0.65 \mathrm{cc}$ Hylenex injected to lower lip and NLFs. Two 
weeks later swelling had significantly decreased and only remaining palpable nodules in lips/cheeks were injected with $1 \mathrm{cc}$ Hylenex. Six weeks later the patient had barely palpable,non-tender nodules in the lower lip/commisures and deferred further treatment at that time (Fig. 7). A summary of treatment intervention is presented in Table 1. Of note, the patient was discontinued from the active trial and did not receive the second scheduled dose of Moderna COVID-19 vaccine. She remained under observation in the Moderna clinical trial. The patient's two subsequent COVID-19 antibody tests were negative. Just prior to article submission, patient was notified by her principle investigator that she received the saline placebo.

\section{Case 3}

Patient three is a healthy 36-year-old female who presented with worsening bilateral infraorbital perioral edema post administration of the Moderna COVID-19 vaccine. The patient had previously received Juvederm ${ }^{\circledR}$ Voluma $^{\mathrm{TM}}$ (Allergan, Irvine CA) within the bilateral tear troughs and $1 \mathrm{cc}$ Juvederm ${ }^{\circledR}$ Ultra (Allergan, Irvine CA) to the upper and lower lip in November 2019. Patient had received fillers in past without any reaction following injections or reactions following vaccinations (Influenza and Hepatitis B) or viral illnesses. She reported no history of angioedema and denied positive COVID testing in past.

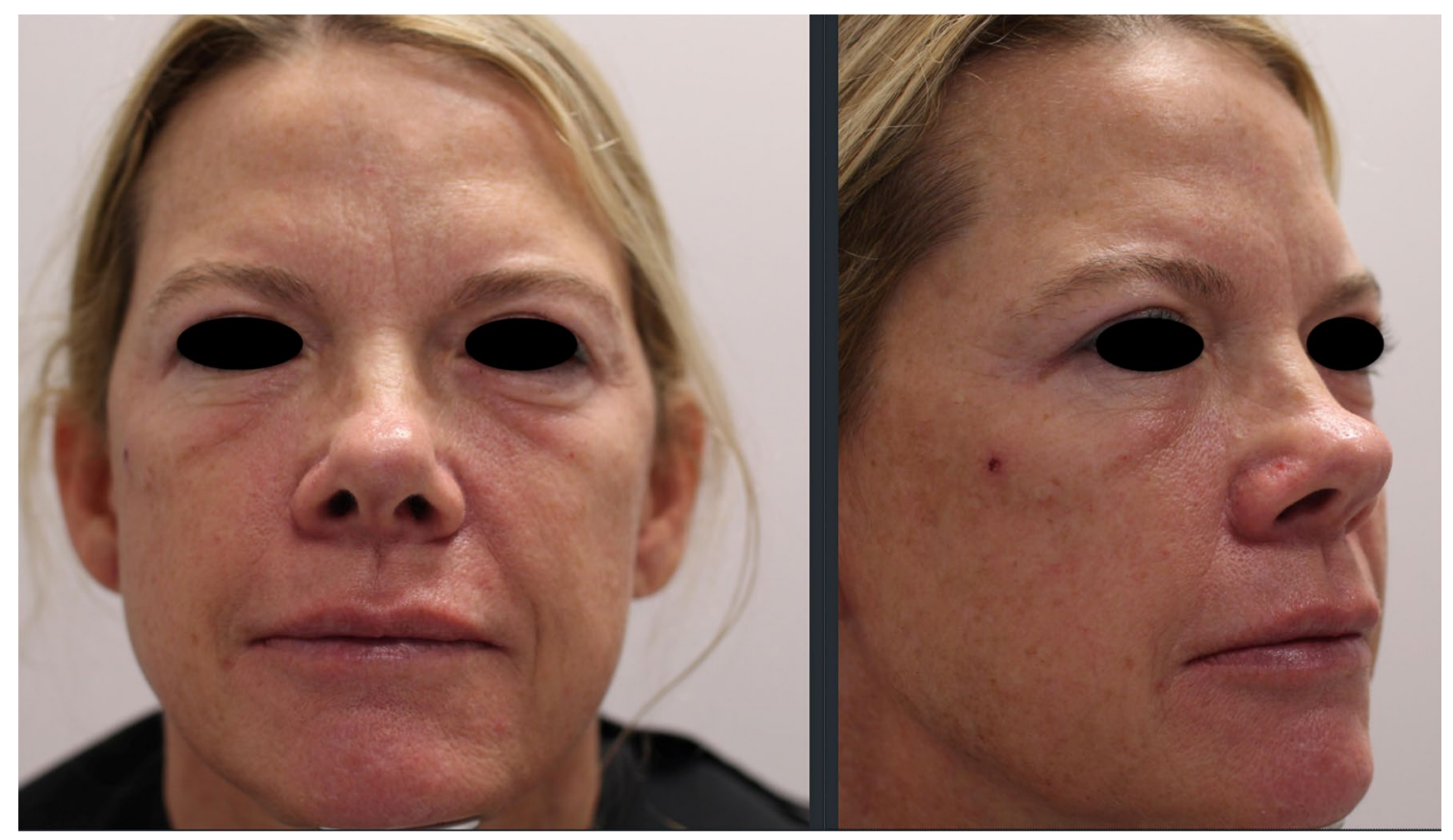

Fig. 7 Marked clinical improvement in Case 2 after prolonged course of multiple therapeutic intervention

Table 1 Total Treatment summary for Case 2 patient over a 4 week course

\begin{tabular}{|c|c|}
\hline Therapeutic intervention & Dosage/caregiver \\
\hline Recombinant hyaluronidase (Hylenex) & $21.65 \mathrm{cc}$ (150 U/cc dispensed in $1 \mathrm{vial})$ \\
\hline Bovine hyaluronidase (compounded) & $9.5 \mathrm{cc}(150$ U.cc $)$ \\
\hline Oral corticosteroids & $\begin{array}{l}\text { Medrol DosePak } \\
60 \mathrm{mg} \text { Prednisone taper over } 12 \text { days } \\
\quad(60 \mathrm{mg} \times 4 \text { days, } 40 \mathrm{mg} \times 4 \text { days } \times 20 \mathrm{mg} \times 4 \text { days })\end{array}$ \\
\hline Oral antimicrobials & $\begin{array}{l}\text { Generic Doxycycline capsules } 100 \mathrm{mg} \text { BID } \times 7 \text { days } \\
\text { Nitrofurantoin } 100 \mathrm{mg} \text { BID } \times 7 \text { days }\end{array}$ \\
\hline Intralesional 5-fluorouracil & $0.8 \mathrm{cc}(50 \mathrm{mc} / \mathrm{cc})$ \\
\hline $\begin{array}{l}\text { Health care providers seen in consultation or treat- } \\
\text { ment }\end{array}$ & $\begin{array}{l}\text { Oculoplastic surgeon, otolaryngology, nurse injector } \\
\text { (at plastic surgery office), dermatologist }\end{array}$ \\
\hline
\end{tabular}

DIR after participating in mRNA 1273 Vaccine Trial 
She received first dose of the Moderna vaccine on $1 / 5 / 2021$. Within the next $12 \mathrm{~h}$ she reported onset of generalized myalgias and fever of $101.6 \mathrm{~F}$. At this time 500 $\mathrm{mg}$ of acetaminophen was taken for symptom management with resolution of fever the following morning. Additionally, the patient noted increased tenderness in the right tear trough. Throughout the day, the unilateral infraorbital edema worsened and perioral edema began to develop. On 1/7/2021, $36 \mathrm{~h}$ post vaccination, $10 \mathrm{mg}$ of certirizine was administered. Evidence of the onset of infraorbital edema and perioral edema within this period can be seen in Fig. 8a, b. Patient reported that at $48 \mathrm{~h}$ post vaccination infraorbital swelling and perioral angioedema was at its peak and she was unable to open the right eye. The patient took $20 \mathrm{mg}$ of cetirizine at that time. Throughout the morning, the left tear trough swelling subjectively increased, while the rest of the face remained persistently swollen, in areas of previous filler injection. The patient was opposed to using oral corticosteroids because of the possibility of nullifying an immune respose to the vaccine. At this time, $5 \mathrm{mg}$ of lisinopril was initiated orally. No further medications (including

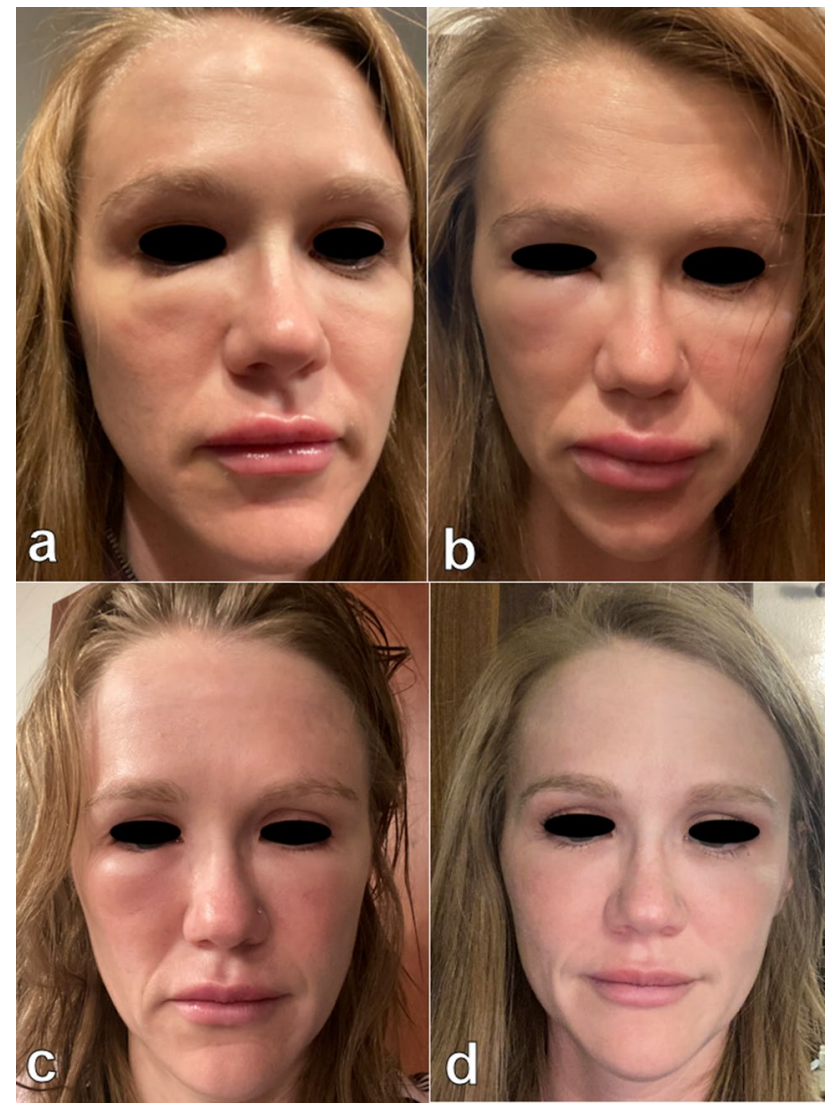

Fig. 8 a 36 h post Moderna COVID-19 vaccination b 48 h post Moderna COVID-19 vaccination c $60 \mathrm{~h}$ post Moderna COVID-19 vaccination d $72 \mathrm{~h}$ post Moderna COVID-19 vaccination, $48 \mathrm{~h}$ post ACE inhibitor initiation antihistamines) were administered from that point forward. Patient reported arrest of left tear trough swelling within $5 \mathrm{~h}$ of lisinopril and improvement of right tear trough swelling. Over a period of $24 \mathrm{~h}$, perioral edema was visible and functionally improved and the patient returned to baseline (Fig. 8c, d).

\section{Case 4}

Patient is a healthy 43-year-old female who had tear trough filler placed over 2.5 years ago. She has no history of angioedema or seasonal allergies. She received the first Pfizer vaccine dose 12/19/2021 and reported only mild arm injection site pain lasting 2 days. A second vaccination was done on 1/7/2021, again with mild arm injection site pain which resolved by the afternoon on $1 / 8 / 2021$. Twenty-four hours later, she noted a mild tenderness underneath the right eye, followed hours later by swelling under the left eye. She started a Medrol dose pack the following day and by $24 \mathrm{~h}$ she noted marked improvement with decrease in tear trough swelling bilaterally (Fig. 9a, b, c).

\section{Discussion}

A recent expert consensus panel defined the duration of DIRs as arising from a normal state 2-4 weeks or longer post-injection [5]. Clinically, they noted that DIRs in HAbased filler injections manifest as erythema, painful nodules, induration, and eyelid edema. The authors also acknowledged that certain triggers might be associated with the onset of DIRs, which can include viral infection, active sinusitis, low-quality products, combinations of different products, improper technique, and past and current dental procedures. Lastly, it was mentioned that DIR can occur in the skin at different sites of injection, chiefly dermal and subcutaneous placement, with adipose tissue being the most common placement site [5].

Based on the historical and temporal events as detailed above, we believe that three of the aforementioned cases demonstrate DIR of HA fillers, triggered by exposure to COVID-19 spike protein. In the one case, the patient exposure to the COVID spike protein was likely achieved following native infection with community-acquired COVID resulted in seroconversion, followed within weeks by DIR. The HA dermal filler involved in this case is classified as monophasic (particles of the same size) $20 \mathrm{mg} / \mathrm{ml}$, non-animal (NASHA) derived, and crosslinked. With a prior history of a recalcitrant eczematous dermatitis, she was being treated with periodic subcutaneous injections of dupliximab at the time of COVID-19 infection. DIR persisted for weeks after COVID infection resolved, prompting evaluation and 


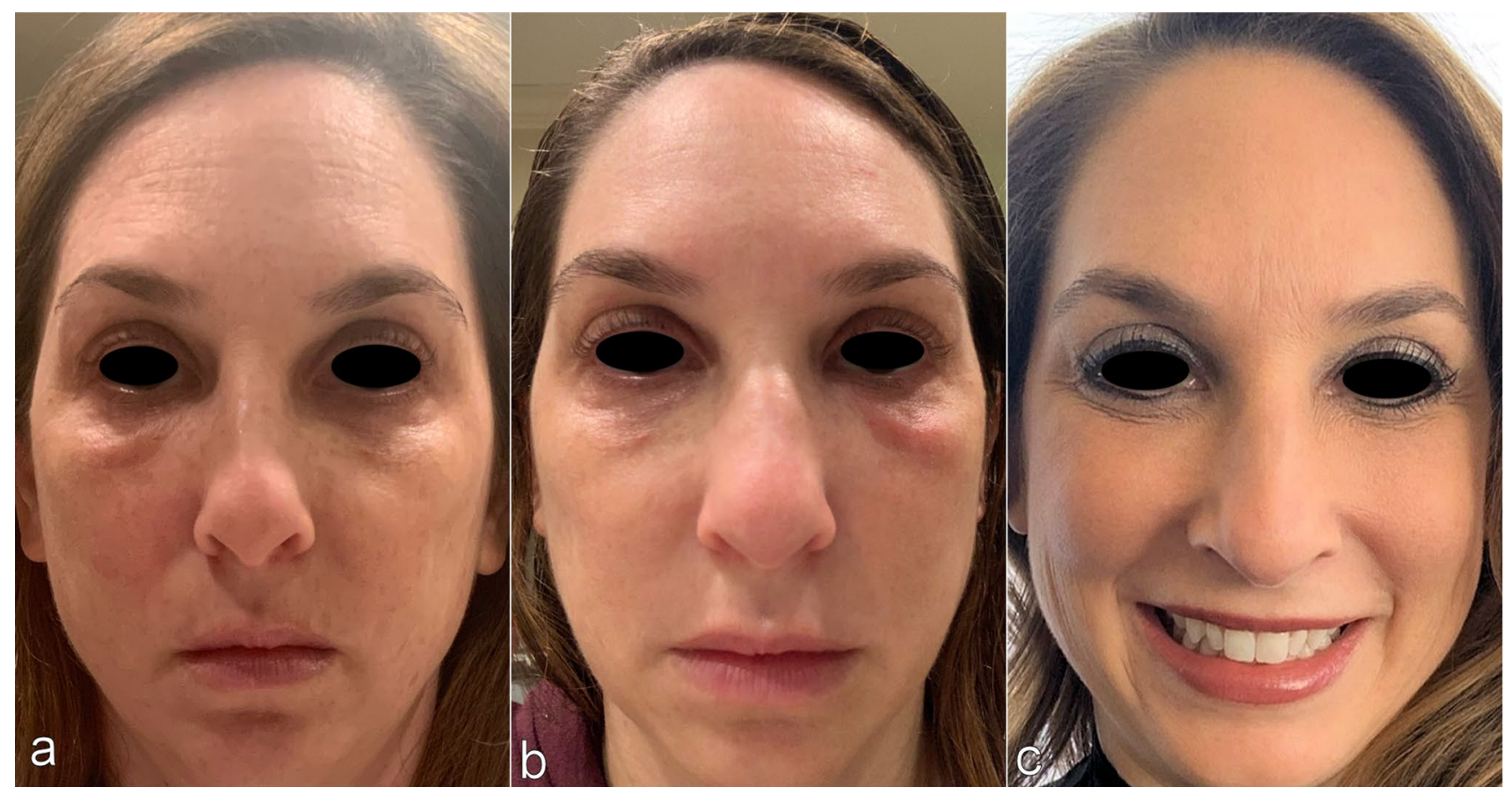

Fig. 9 Case $4 \mathbf{a}$ initial appearance of DIR to HA placed in the right tear trough, $\mathbf{b}$ inflammation extending to left tear trough (c) resolution of inflammation and majority of the swelling

treatment. Persistent areas of involvement included the previously-injected areas of the tear trough, periorbita, and medial cheeks. The treatment course was difficult, requiring multiple rounds of oral corticosteroids, multiple sessions of intralesional recombinant hyaluronidase, and physical thermal dissolution of the HA by use of a bipolar radiofrequency microneedle device. Although symptomatology greatly improved, evanscent swelling in the peroribtial area still persisted, likely due to residual HA product.

In the second case, the patient was a subject following the Moderna mRNA-1273 trial protocol. Although the trial was conducted as a double blinded, placebo-controlled trial, the patient felt certain that her first vaccine dose to be to be the actual vaccine. Furthermore, she experienced lingering pain in that arm for days following the injection. Saline served as placebo control in this trial because it is highly unlikely to trigger any biologic response.

Eight days following the injection per protocol (without constitutional symptoms or known community COVID exposure), she began to experience the onset of DIR in the periorbital area. This was followed within days by inflammation occurring in previous facial injection sites: firstly the earlobes (performed 18 months prior to the vaccination) and secondly more intense inflammation in the malar cheeks, tear troughs, nasolabial folds, and lips (sites more recently injected 5 weeks prior to the vaccination). Per patient history, she was barred to proceed with the second vaccination dose in the trial due to the concomitant usage of oral corticosteroids, which were used in high doses to qwell the ongoing DIR. A scheduled blood test was carried out per protocol and did not reveal seroconversion following the first dose. Given the scenario, the patient and the primary author felt certain she received the vaccine; however, unblinding of the data revealed that she was given saline placebo. Without confirmation of seropositiviy, and in the absence of any historical trigger factors, the definitive cause of DIR remains unknown. The severity of her inflammatory reaction necessitated multiple treatment measures which although ultimately successful, came at great expense.

It is worth noting that two other cases of DIR reaction to injectible HA fillers occurred (labelled as serious adverse events) in the mRNA-1273 trial [11]. The Moderna FDABriefing document details three related cases of hypersensitivity reaction to previous facially-injected dermal filler. In one case, a 46-year-old caucasian female received injections in her cheeks of Juvederm XC in March 2020. In the study, she received her first dose on August 31, 2020, and her second dose on September 29, 2020. Between September 30 and October 5 2020, she developed significant bilateral cheek swelling with no rash, pain, tenderness, oral or respiratory symptoms. Symptoms were considered moderate and the reaction designated as serious. The study participate received diphenhydramine and methylprednisolone and recovered (data on file with Moderna).

In the second Moderna trial case, a 51-year-old caucasian female received Juvederm and Botox injections in her 
cheeks on October 2, 2020. The study participant received her first vaccine dose on September 12, 2020, and her second dose on October 15, 2020. Between October 17 and 22 she developed bilateral facial swelling with the left side being more pronounced. Swelling was measured at $125 \mathrm{~mm}$ on day 3 and $55 \mathrm{~mm}$ on day 4 post-vaccination. Symptoms were considered moderate and the reaction designated as serious. The study participant received Prednisolone and recovered (data on file with Moderna). In a third case involving lip swelling of a 29-year-old female that occurred 2 days after vaccine injection, the reaction was termed angioedema and was classified as medical significant. This case had a history of prior dermal filler placement to the lips, of unknown duration prior to the trial [11].

As of August 2020, thirty potential vaccines against COVID-19 were in clinical trials with another 139 in pre-clinical development, including both gene-based (mRNA, DNA) and protein-based candidates [12]. Genetic approaches have the benefit of eliciting antibodies and CD4+ helper T cells, they recruit CD8+cytotoxic T cells, through the major histocompatibility class I pathway [12]. COVID-19 prevention efforts represent the first large scale usage of mRNA technology for vaccine development. As such, understanding of complete clinical response to mRNA vaccines is unknown. Published data from the three major completed COVID vaccine trials Phase I,II, and III in the United States/UK/Brazil/South Africa include mRNA1273 vaccine (Moderna), ChAdOx $1 \mathrm{nCoV}-19$ vaccine (Astrazenica) and RNA vaccine BNT162b1(Pfizer-BioNTech) has mandatorily included reporting of adverse events [13-18]. Table 2 summarizes the known cutaneous adverse events from these studies. Transient urticaria and pruritus were noted for the mRNA-1273 trial, while rosacea flaring occurred in the ChAdOx $1 \mathrm{nCoV}-19$ vaccine trial. No incidences of DIR were reported publically for the Pfizer or Astrazenica trials at the time of this submission. Presumably, this is because either they did not occur, or as in the case of mRNA-1273, the numbers did not meet the minimum threshold incidence within the protocol for reporting as serious adverse events.
The Vaccine Adverse Event Reporting System (VAERS) is an online, self-reporting database developed by the CDC and utilized for reporting adverse events from vaccination, performed on the general public [19]. Vaccination cards given after COVID immunization contain the website address and strongly encourage self-reporting of any side effects. A query was performed of VAERS from the inclusive dates of Pfizer and Moderna vaccine public release until Jan $10^{\text {th }} 2020$, using database terms to identify cutaneous post-immunization reactions. Of the 641 records of patients who self-reported skin-related issues following receiving either the first or both vaccine doses, 152 of those cases were found to include the term (or synonyms for term) "edema" with regards to visible skin swelling (Fig. 10). DIR, though not characterized by extensive soft tissue involvement, can be misdiagnosed as edema, facial edema or angioedema because of the presence of acute onset swelling involving the skin and lips.

DIR as a response to other viral vaccination has been reported sparsely in the literature. One report from Brazil detailed the characteristic induration, edema, and erythema of DIR in a patient in weeks following the administration of the influenza vaccine [20]. The author has personal experience with two patients experiencing DIR with calcium hydroxylapatite (Radiesse, Merz, Germany) filler treatment to the face and hands, respectively, following the first dose of administration of the shingles vaccine (author observation).

Of significance, a variety of HA products were used in the aforementioned cases, and contain different stabilizing/ crosslinking formulations, purification, and composition. Artzi and colleagues noted (based on a review of available literature), that the reported rate DIR prior to 1999 were $0.7 \%$ and that rate began to decrease after the introduction of highly purified HA products to $0.2 \%$. [21]. In the 400 subjects studied retrospectively, the authors did not report a DIR related to post viral illness or vaccination [21]. However, several studies have shown that the biphasic highlycrosslinked Juvederm vycross filler product line has a higher than expected rate of DIR [3, 5, 22]. It is has been reported

Table 2 Summary of cutaneous adverse reactions in current USA/UK/Brazil/South Africa based COVID Clinical Trials

\begin{tabular}{|c|c|c|c|}
\hline Sponsor & Vaccine & Phase trial & Reported cutaneous adverse reactions (non-injection site related) in vaccine groups \\
\hline AstraZenica & ChAdOx1 nCoV-19 & I,II,III & Rosacea flare, Pruritus; cellulitis \\
\hline Moderna & mRNA-1273 & $\mathrm{I} / \mathrm{II} / \mathrm{III}$ & $\begin{array}{l}-1 \text { instance of transient urticaria on both legs } 5 \text { days after receiving first dose of } \\
\text { vaccine } 25 \text { mcg vaccine; } \\
-1 \text { instance of a maculopapular rash } \\
-2 \text { instances of hypersensitivity reaction to previously injected facial dermal filler } \\
\text { (deemed serious adverse events) } \\
-1 \text { instance of angioedema of lips in subject with history of lip dermal filler injec- } \\
\text { tion }\end{array}$ \\
\hline Pfizer-BioNTech & BNT162b2 & I,II,III & Hypersensitivity-related adverse events 137 participants, $0.63 \%$ \\
\hline
\end{tabular}




\section{Query Criteria:}

Title:

State / Territory:

Symptoms:

Vaccine Products:

\section{VAERS ID:}

Group By:

Show Totals:

Show Zero Values: False

All

False

False

\section{Adverse Skin Reactions}

The United States/Territories/Unknown

ADMINISTRATION SITE OEDEMA; ADMINISTRATION SITE RASH; ALLERGIC OEDEMA; ANGIOEDEMA; DERMATITIS ALLERGIC; DERMATITIS CONTACT; DRUG ERUPTION; ERYTHEMA; EXFOLIATIVE RASH; EYELID OEDEMA; EYELID RASH; FACE OEDEMA; HEAT RASH; HEREDITARY ANGIOEDEMA; IDIOPATHIC ANGIOEDEMA; INJECTION SITE BRUISING; INJECTION SITE DERMATITIS; INJECTION SITE ECZEMA; INJECTION SITE ERYTHEMA; INJECTION STTE GRANULOMA; INJECTION SITE INOURATION; INJECTION SITE INFLAMMATION; INJECTION SITE MACULE; INJECTION SITE NODULE; INJECTION SITE OEDEMA; INJECTION SITE RASH; INJECTION SITE REACTION; INJECTION SITE URTICARIA; INJECTION SITE VASCULITIS; INJECTION SITE VESICLES; LIP OEDEMA; MUCOCUTANEOUS RASH; NODULAR RASH; OEDEMA; ORAL MUCOSAL. ERUPTION; PUNCTURE SITE OEDEMA; PURPURA; RASH; RASH GENERALISED; RASH MACULAR; RASH MACULO-PAPULAR; RASH PRURITIC; RASH VESICULAR; SKIN OEDEMA; URTICARIA; VACCINATION SITE OEDEMA; VACCINATION SITE RASH; VASCULITIC RASH; VIRAL RASH

COVID19 VACCINE (COVID19)

Vaccine Dose; VAERS ID

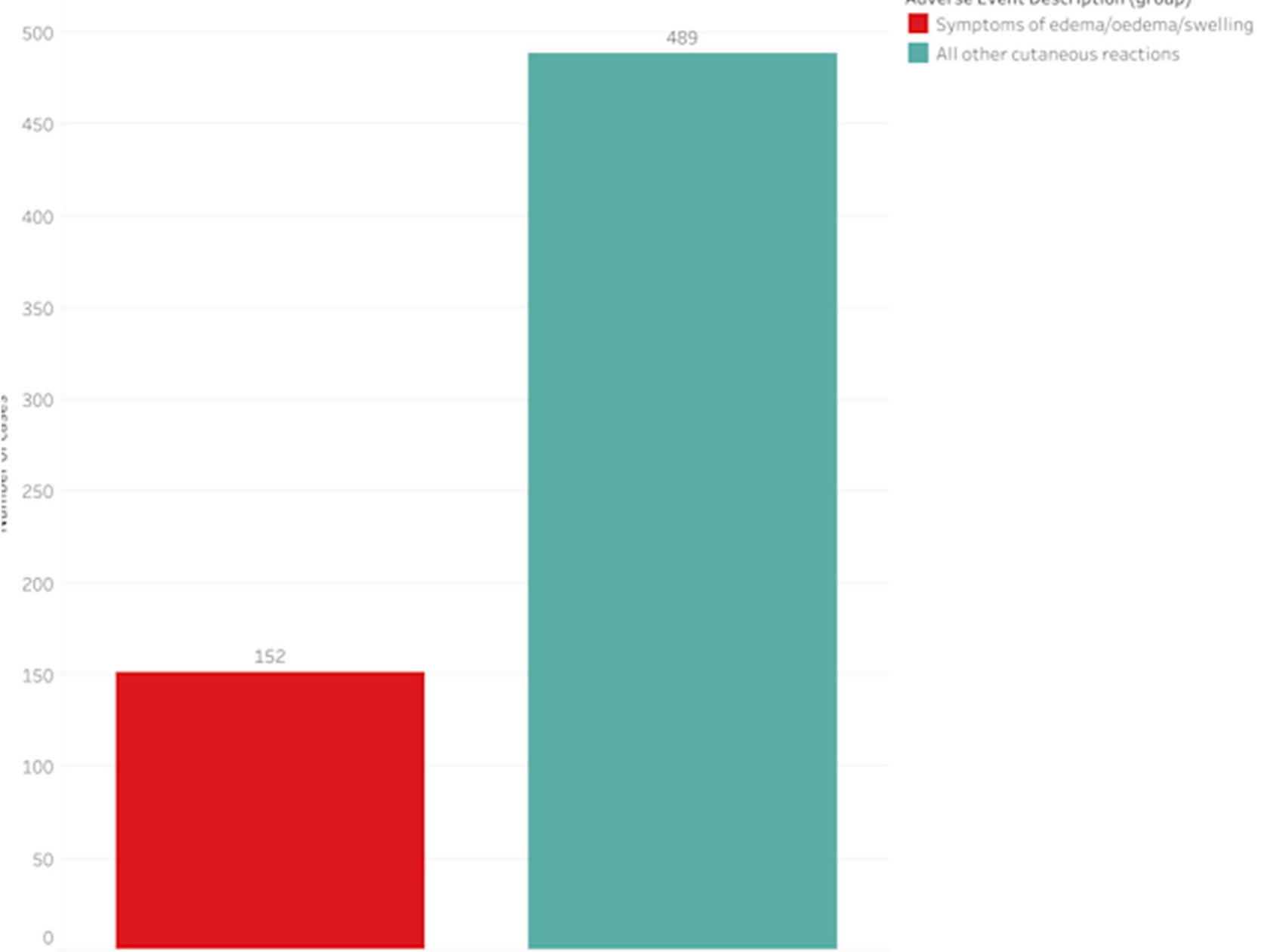

Fig. 10 Query of the VAERS database with possible terms specific for cutaneous adverse events yielded 641 cases, with 152 cases linked to edema of the skin 
that HA-based fillers with a low-molecular weight-degraded products have higher pro-inflammatory activity [5].

Recent reports in the literature have revealed an incidence of DIRs to Juvederm Volbella of $1.0 \%$ per patient and $0.8 \%$ per syringe, which is higher than the previously reported incidence of $0.02 \%$ and more compatible with the $4.25 \%$ incidence of DIRs to Juvederm Volbella previously reported by Artzi et al. [5, 21]. Analysis of the U.S. Food and Drug Administration (FDA) MAUDE database by Ortiz et al. identified the Juvederm family of dermal HA fillers with a high risk profile amongst HA fillers for development of DIR [23]. Comparatively, the incidence rate of hypersensitivity reactions to the monophasic NASHA fillers has been reported at $0.8 \%$, with the rate for delayed reactions reported at $0.3 \%$. Time to onset of delayed nodules ranged from 1 month to 3 years after HA implantation [3].

As longevity of HA filler increases with newer products, DIR incidence could increase, simply as a function of the presence of a persistent nidus for inflammation. The need for accurate medical recording of anatomic placement and specific filler type (specific HA vs other non-HA fillers) will become more important. A recent small study, utilizing a novel HA-specific Magnetic Resonance (MR) imaging modality, identified filler that had been placed in to subjects 6 years prior [24]. Subjects, which denied filler placement for 2 years prior and denied placement in certain anatomic areas, were indeed found on MR to have residual HA filler in those areas [24]. Therefore, it is reasonable to expect that in future vaccine trials, effort should be dedicated to get an accurate medical history of dermal filler placement as part of the subject screening process.

Cutaneous manifestations of COVID-19 can present with a constellation of cutaneous signs, occurring concurrent/ after the onset of the characteristic pyrexia, anosmia/hyposmia, ageusia, and respiratory symptoms [25]. Although chilblains-like eruptions of the digits/toes, petechiae, and acro-ischemia, have been reported, only urticaria has been reported along the spectrum of delay-type hypersensitivity reactions described in the two cases above [26] (Fig. 11). In a recent meta-analysis of 44 articles with 507 patient cases, the most common cutaneous findings were polymorphic eruptions, erythema, chilblain-like lesions, and urticarial lesions, occurring on an average of 9.92 days (range: 1-30) after the onset of systemic symptoms [25]. In humans, ACE2 is expressed in the skin in multiple cell types. The ARCHS4 database is publicly available and has demonstrated the resident skin cell types associated with high levels of ACE2, including fibroblast and keratinocytes [27] (Fig. 12). Interestingly, Li et al. showed that adipose tissue has also been shown to contain high levels of ACE2 [8], wherein may lie a majority of the filler placed anatomically in the face.

The Zhao study also evaluated the role of ACE2 constituitive expression in the cutaneous manifestations of

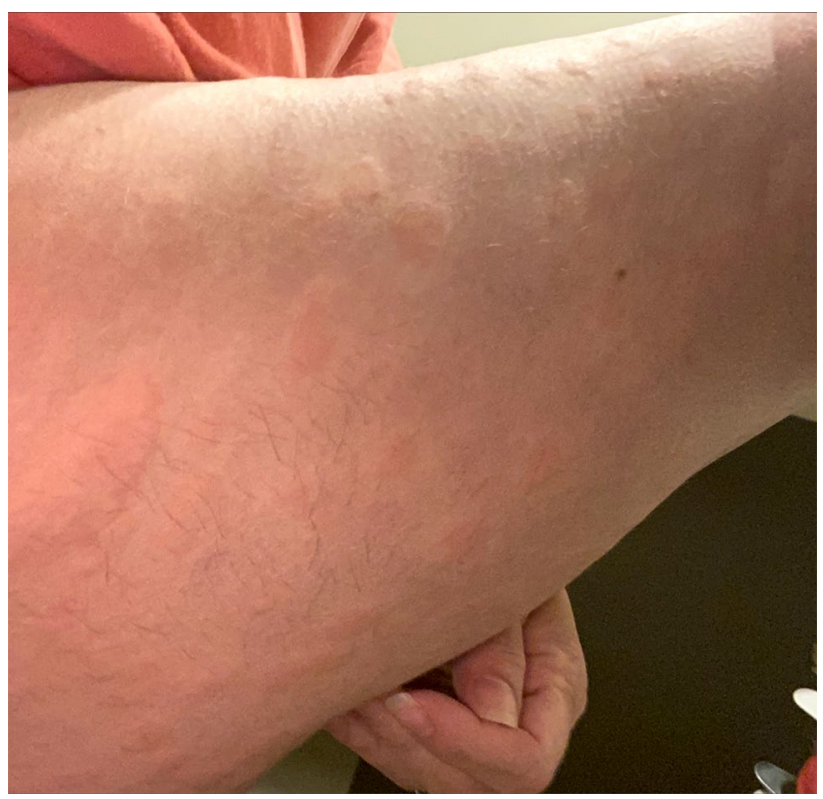

Fig. 11 Clinical manifestation of urticaria in a COVID-19 patient who presented to the authors during a telemedicine consultation

COVID-19 [25]. They found higher than expected levels of ACE2 expression in keratinocytes of COVID-19 patients who also had detectible viremia and skin lesions [25].

One possible explaination for COVID spike protein related to DIR with HA fillers could be explained by the genesis of the HA filler granuloma, a seminal imflammatory event. Failure of effective phagocytosis of longstanding HA, coupled with biofilm formation, and direct $\mathrm{T}$ cell activation common of bio-implants can lead to fibrosis and granuloma formation, favoring a TH1/CD $8+\mathrm{T}$ cell presence $[28,29]$. In tissue, including the skin, a relative higher concentration of ACE2 are present to maintain immune homestasis, by regulating the production of proinflammatory angiotensin II relative to levels of the metabolites, angiotensin 1-7 (anti-inflammatory). However, ACE2 is a ligand for the COVID spike protein and active infection can bind available ACE2, further tipping the balance in favor of angtiotensin II and development of a proinflammatory response. Additional studies have detailed the presence of ACE2 in the cutaneous endothelium of $\mathrm{mid} /$ deep dermal and subcutaneous microvasculature [30]. Complement-mediated destruction of cutaneous microvasculature, secondary to docking by SARS-CoV-2 spike protein, has also been demonstrated [30]. The implantation of dermal HA filler is known to stimulate angiogenesis and retain neovascularity in human and murine models [31]. Therefore, the possibility exists that higher (than baseline) dermal and subcutaneous levels of ACE2 are localized in the vicinity of acute and chronic injected cutaneous HA filler boluses, setting the stage for an peri-bolus filler DIR 

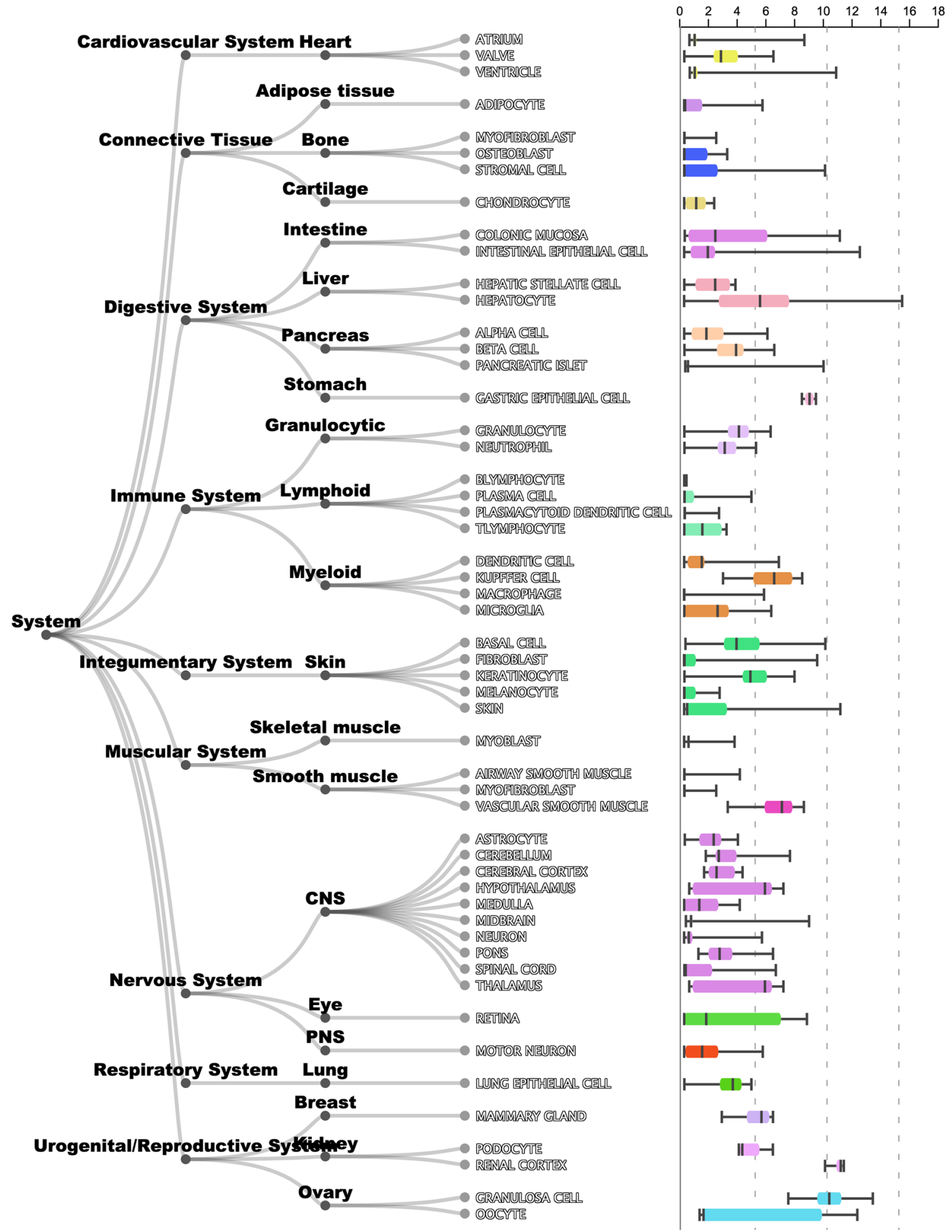

Fig. 12 Data from the ARCHS4 database, https://maayanlab.cloud/archs4/, showing the relative expression of ACE2 levels in different organ systems (subcategorized by cell type) in the body

triggered by occlusion occurring post-vaccine or during/ after active COVID-19 infection.

Based on this concept, in the third case with evolving DIR post Moderna vaccination, we investigated a hypothesis that ACE-I could potentially modulate DIR as a treatment option. Since ACE2 is bound by spike protein, it is essentially otherwise engaged and unable to convert angiotensin II to angiotensin 1-7. By reducing the levels of angiotensin II 
with ACE-I, this burden on ACE2 may be lessened, mitigating the effects of rising levels of spike protein. In this single case ancedote, treatment with an oral ACE-I may have had a positive effect in rapidly reducing the edema and inflammatory response secondary to rising angiotensin II levels, in a non-immunosuppresive way, unlike CS which could potentially blunt antibody response to the virus. As an additional mechanism of reducing interstitial edema, lisinopril decreases angiotensin II-induced aldosterone secretion by the adrenal cortex, which leads to an increase in sodium excretion and subsequently increases water outflow.

The literature details that a viral vaccine or illness can serve as a DIR triggering event. Published works have documented cases after viral illness [3, 6, 32, 33]. Turkmani et al. described 14 cases of HA DIR following an influenza-like illness [6]. In all cases, subjects had no allergies or other predisposing autoimmune or infectious conditions. HA filler was present 2-8 months prior to developing the DIR, and patients experienced DIR within 3-5 days of developing the influenza-like illness. A variety of different branded HA fillers were used in these patients, and the most common anatomic areas affected were the cheeks, tear trough, and lips. In this series, most of the patients responded to oral corticosteroids only, while a few required addition intervention with intralesional hyaluronidase injections.

Bhojani-Lynch also described a series of 5 patients with DIR, 4 of which reported an influenza-like illness a few days prior to the onset of inflammation [33]. The author used a similar management approach of oral CS to suppress inflammation quickly, utilizing the hyaluronidase for persistent or non responsive areas of inflammation [33]. In the COVID cases reported in the USA, both oral and IV prednisone clinically improved edema and pain. Whereas the SARS-CoV-2 targets the ACE2 receptor for cell entry, Xiang et al. described CS as one part of a multi-step approach for COVID-19 respiratory symptom management through ACE2 agonistic activity [34]. Of potential clinical significance, Artzi et al. made mention of smaller nodules being more frequently observed in conjunction with viral illness or post dental procedures, which tended to heal spontaneously [3].

One final clinical observation in our three confirmed COVID-related cases is with regards to time of onset of the symptoms. There is a significant difference in the time of onset of DIR in the first case, which started weeks after COVID seroconversion and the vaccine-related cases, which started days after vaccination. Case 4 interesting did not show evidence of DIR until the second dose. One potential explaination may be due to the more rapid rise in serum (and subsequent dermal concentration) of the spike protein in the vaccination cases, because of the rapid production due to the nature of the mRNA vaccine. Native COVID exposure and seroconversion may result in a longer rise in serum protein levels, as the virus takes more time to evade the host immunosurveillance, replicate, and produce appreciable levels of spike protein.

\section{Conclusion}

We have presented three cases of a COVID-19 spike protein triggered inflammatory reaction to dermal HA filler. Could this be a microcosm of what is to come in the perfect storm of: (1) the exploding popularity of dermal fillers for aesthetic facial enhancement (2) the rising cases of COVID19 and (3) expected widespread deployment of COVID-19 mRNA vaccines? Although the exact mechanism of DIR is unknown, we hypothesize that the COVID-19 spike protein evokes a pro-inflammatory response in the location of dermal HA fillers through blockade of a cutaneous ACE2 inhibitory pathway. Whether the DIR is related specifically to the mRNA-1237 vaccine or is a potential adverse reaction to widespread immunosurveillance following infection is to be determined.

Prevention of DIR should include a thorough history and patient education. When consulting patients for dermal fillers, active skin infections are historically contraindicated from treatment. However, a history of recent viral illness, dental or other potential bacterial seeding procedures, or recent/upcoing vaccination schedule is not elicited [35]. Clinical evaluation of similar cases in similar settings should consider the interplay between viral illness, cutaneous facial inflammation, and HA dermal fillers. Therapeutic management in extensive, symptomatic cases should consider a combination of oral CS and hyaluronidase injections initially to reduce the inflammatory response, stimulate ACE2 upregulation, and eliminate the HA nidus of the inflammation. Notably, the administration of oral CS to treat an active/ ongoing viral infection is usually avoided to avoid inhibition of host immune response. However, in the case of COVID19, SARS-CoV-2 stimulates what appears to be a hyperimmune response, that benefits from corticosteroid administration. This is evidenced by the now routine practice of CS administration for acute COVID-19 infection. Infectious Diseases Society of America (IDSA) guidelines recommend the use of corticosteroids in active infection among hospitalized patients with severe COVID-19 disease [36]. Another potential option, which merits further evaluation, would be the use of ACE-I or angiotensin receptor blockers (ARBs) in the the acute phase treatment of DIR in this specific setting based on knowledge of the Angiotensin pathways in the body $[37,38]$. Other possibilities of ACE-I therapy would include pre-treatment to prevent DIR prior to first vaccine dose in a patient with longstanding history of filler placement or pretreatment of a patient prior to second vaccine dose, if a DIR develops after the first dose. Therapeutic 
intervention with ACE-I or ARB would not be expected to affect vaccine efficacy in a similar manner to $C S$.

\section{Compliance with ethical standards}

Informed consent Written informed consent for publication of their clinical details and/or clinical images was obtained from the patient/ parent/guardian/ relative of the patient. A copy of the consent form is available for review by the Editor of this journal.

\section{References}

1. https://www.asds.net/medical-professionals/practice-resources/ asds-survey-on-dermatologic-procedures. Accessed 12 Jan 2021

2. https://www.marketquest.biz/report/32360/global-hyaluronic -acid-based-dermal-fillers-market-2020-by-manufacturers-regio ns-type-and-application-forecast-to-2025. Accessed 12 Jan 2021

3. Humphrey S, Jones DH, Carruthers JD et al (2020) Retrospective review of delayed adverse events secondary to treatment with a smooth, cohesive $20-\mathrm{mg} / \mathrm{mL}$ hyaluronic acid filler in 4500 patients. J Am Acad Dermatol 83(1):86-95

4. Dayan SH, Arkins JP, Somenek M (2012) Restylane persisting in lower eyelids for 5 years. J Cosmet Dermatol 11(3):237-238

5. Artzi O, Cohen JL, Dover JS, Suwanchinda A, Pavicic T, Landau M, Goodman GJ, Ghannam S, Al Niaimi F, van Loghem JAJ, Goldie K, Sattler S, Cassuto D, Lim TS, Wanitphakdeedecha R, Verner I, Fischer TC, Bucay V, Sprecher E, Shalmon D (2020) Delayed inflammatory reactions to hyaluronic acid fillers: a literature review and proposed treatment algorithm. Clin Cosmet Investig Dermatol 18(13):371-378

6. Turkmani MG, De Boulle K, Philipp-Dormston WG (2019) Delayed hypersensitivity reaction to hyaluronic acid dermal filler following influenza-like illness. Clin Cosmet Investig Dermatol $12: 277-283$

7. Verdecchia P, Cavallini C, Spanevello A et al (2020) The pivotal link between ACE2 deficiency and SARS-CoV-2 infection. Eur J Intern Med 76:14-20

8. Li M, Li L, Zhang Y, Wang X (2020) Expression of the SARS$\mathrm{CoV}-2$ cell receptor gene ACE2 in a wide variety of human tissues. Infect Dis Poverty 9(1):45

9. Scholzen TE, Ständer S, Riemann H, Brzoska T, Luger TA (2003) Modulation of cutaneous inflammation by angiotensin-converting enzyme. J Immunol 170:3866-3873

10. Ni W, Yang X, Yang D et al (2020) Role of angiotensin-converting enzyme 2 (ACE2) in COVID-19. Crit Care 24:422

11. https://www.fda.gov/media/144434/download. Accessed 12 Dec 2021

12. Abbasi J (2020) COVID-19 and mRNA vaccines-first large test for a new approach. JAMA 324(12):1125-1127

13. Jackson LA, Anderson EJ, Rouphael NG et al (2020) An MRA vaccine against SARS-CoV-2-preliminary report. N Engl J Med 383(20):1920-1931

14. Baden LR, El Sahly HM, Essink B, Kotloff K, Frey S, Novak R, T, et al (2020) COVE Study Group. Efficacy and Safety of the mRNA-1273 SARS-CoV-2 Vaccine. N Engl J Med. https://doi. org/10.1056/NEJMoa2035389

15. Mulligan MJ, Lyke KE, Kitchen N et al (2020) PhaseI/II study of COVID-19 RNA vaccine BNT162b1 in adults. Nature 586:589_ 593. https://doi.org/10.1038/s41586-020-2639-4
16. Walsh EE, Frenck RW Jr, Falsey AR et al (2020) Safety and immunogenicity of two rna-based Covid-19 vaccine candidates. N Engl J Med 3883:2439-2450

17. Ramasamy MN, Minassian AM, Katie J, Ewer KJ et al (2020) Safety and immunogenicity of ChAdOx $1 \mathrm{nCoV}-19$ vaccine administered in a prime-boost regimen in young and old adults (COV002): a single-blind, randomised, controlled, phase $2 / 3$ trial. Lancet 396:1979-1993

18. Voysey MV, Costa Clemens SA, Madhi SA, Weckx LY, Folegatti PM, Aley PK (2020) Safety and efficacy of the ChAdOx1 nCoV-19 vaccine (AZD1222) against SARS-CoV2: an interim analysis of four randomised controlled trials in Brazil, South America, and the UK. Lancet S0140-6736(20):32661-32671

19. https://wonder.cdc.gov/controller/datarequest/D8; jsessionid =DD7D49AC9C683DB4DEBE7E98834C. Accessed 12 Jan 2021

20. Cavallieri FA, Balassiano LK, de Bastos JT, Fontoura GH, de Almeida AT (2017) Persistent, intermitent delayed swelling PIDS: late adverse reaction to hyaluronic acid fillers. Surg Cosmet Dermatol 9(3):218-222

21. Artzi O, Loizides C, Verner I, Landau M (2016) Resistant and recurrent late reaction to hyaluronic acid-based gel. Dermatol Surg 42(1):31-37. https://doi.org/10.1097/DSS.0000000000 000562 (PMID: 26655699)

22. Sadeghpour M, Quatrano NA, Meshkov Bonati L, Arndt KA, Dover J, Kaminer MS (2019) Delayed-onset nodules to differentially crosslinked hyaluronic acids: comparative incidence and risk assessment. Dermatol Surg 45(8):1085-1094

23. Ortiz AE, Ahluwalia J, Song S, Avram MM (2020) Analysis of US food and drug administration data on soft-tissue filler complications. Dermatol Surg 47:958-961

24. Master M (2021) Hyaluronic acid filler longevity and localization: magnetic resonance imaging evidence. Plast Reconstr Surg 147(1):50e-53e. https://doi.org/10.1097/PRS.0000000000 007429 (PMID: 33002985)

25. Zhao Q, Fang X, Pang Z, Zhang B, Liu H, Zhang F (2020) COVID-19 and cutaneous manifestations: a systematic review. J Eur Acad Dermatol Venereol. https://doi.org/10.1111/jdv.16778

26. Wollina U, Karadağ AS, Rowland-Payne C, Chiriac A, Lotti T (2020) Cutaneous signs in COVID-19 patients: a review. Dermatol Ther 33:5

27. Lachmann A, Torre D, Keenan AB, Jagodnik KM, Lee HJ, Wang L, Silverstein MC, Maayan A (2018) Massive mining of publicly available RNA-seq data from human and mouse. Nat Commun. https://doi.org/10.1038/s41467-018-03751-6

28. Alijotas-Reig J, Fernández-Figueras MT, Puig L (2013) Inflammatory, immune-mediated adverse reactions related to soft tissue dermal fillers. Semin Arthritis Rheum 43(2):241-258

29. Alijotas-Reig J, Fernández-Figueras MT, Puig L (2013) Lateonset inflammatory adverse reactions related to soft tissue filler injections. Clin Rev Allergy Immunol 45(1):97-108

30. Magro CM et al (2019) Docked severe acute respiratory syndrome coronavirus 2 proteins within the cutaneous and subcutaneous microvasculature and their role in the pathogenesis of severe coronavirus disease. Hum Pathol 106(2020):106-116

31. Mochizuki M, Aoi N, Gonda K, Hirabayashi S, Komuro Y (2018) Evaluation of the in vivo kinetics and biostimulatory effects of subcutaneously injected hyaluronic acid filler. Plast Reconstr Surg 142(1):112-121

32. Beleznay K, Carruthers J, Carruthers A, Mummert ME, Humphrey S (2015) Delayed-onset nodules secondary to a smooth cohesive $20 \mathrm{mg} / \mathrm{ml}$ hyaluronic acid filler: cause and management. Dermatol Surg 41(8):929-939

33. Bhojani-Lynch T (2017) Late-onset inflammatory response to hyaluronic acid dermal fillers. Plast Reconstr Surg Glob Open 5(12): 1532 
34. Xiang Z, Liu J, Shi D, Chen W, Li J, Yan R (2020) Glucocorticoids improve severe or critical COVID-19 by activating ACE2 and reducing IL-6 levels. Int J Biol Sci 16(13):2382-2391

35. Lafaille P, Benedetto A (2010) Fillers: contraindications, side effects and precautions. J Cutan Aesthet Surg 3(1):16-19

36. https://www.idsociety.org/practice-guideline/covid-19-guidelinetreatment-and-management/. Accessed 12 Jan 2021

37. McLachlan CS (2020) The angiotensin-converting enzyme 2 (ACE2) receptor in the prevention and treatment of COVID-19 are distinctly different paradigms. Clin Hypertens 26:14
38. https://www.thelancet.com/journals/ebiom/article/PIIS23523964(20)30282-6/fulltext. Accessed 12 Jan 2021

Publisher's Note Springer Nature remains neutral with regard to jurisdictional claims in published maps and institutional affiliations.

\section{Authors and Affiliations}

\section{Girish Gilly Munavalli ${ }^{1,2}\left(\mathbb{D} \cdot\right.$ Rachel Guthridge $^{1} \cdot$ Siri Knutsen-Larson ${ }^{3} \cdot$ Amy Brodsky $^{4} \cdot$ Ethan Matthew $^{3}$. Marina Landau ${ }^{5}$}

1 Dermatology, Laser, and Vein Specialists of the Carolinas, PLLC, Charlotte, NC, USA

2 Department of Dermatology, Wake Forest School of Medicine, Winston Salem, NC, USA

3 South Dakota Sanford School of Medicine, Vermillion, SD, USA
4 The Derm-Glenview, Glenview, IL, USA

5 Arena Dermatology, Herzliya, Israel 